\title{
Fetal alcohol and the right to be born healthy...
}

\author{
Shiva M. Singh ${ }^{1,2 *}$, Benjamin I. Laufer ${ }^{1}$ and Joachim Kapalanga ${ }^{3}$ \\ ${ }^{1}$ Molecular Genetics Unit, Department of Biology, The University of Western Ontario, London, ON, Canada \\ 2 Department of Neuroscience, The University of Western Ontario, London, ON, Canada \\ ${ }^{3}$ Department of Pediatrics, Schulich School of Medicine and Dentistry, The University of Western Ontario, London, ON, Canada \\ *Correspondence: ssingh@uwo.ca
}

Edited by:

Stephen Mason, Indiana University School of Medicine, USA

Reviewed by:

Gregg Stanwood, Vanderbilt University, USA

Keywords: teratogen, spectrum disorders, neurodevelopment, neuroepigenomics, pregnancy, exposure, environment, fetal alcohol syndrome

Finding the cause and applying the insights toward prevention and treatment forms the ultimate goal of most disease research. This strategy has been successfully used to make diseases like Scurvy and Smallpox, a history. The impact of this research during the last few years has been nothing less than miraculous. More and more people are living longer with healthy and productive lives, well into the 80's and 90's. Discovery of the cause(s) of disease(s) however is a demanding, time consuming, and expensive exercise. Also, there is no guarantee for success. Yet, even the modest success in search for causes have the potential to change the outcome and perception. Early diagnosis of a number of cancers for example is now viewed as treatable with reasonable chance of recovery. Also, some heart diseases are being managed and treated with high rate of success. Given this record of success, the research on disease causations continues to increase and the results have begun to pay increasing dividend. Unfortunately, there are cases of diseases where even full understanding of the cause has not resulted in the prevention or treatment of some common and devastating diseases. One such disease is the fetal alcohol spectrum disorder (FASD).

FASD is caused by the exposure of developing fetus to alcohol via maternal drinking during pregnancy (Jones and Smith, 1973). It represents the biggest single cause of mental retardation and developmental disabilities among babies born in the Western World (Barry et al., 2009). In the U.S. more than 50,000 babies are born with FASD every year (May and Gossage, 2001) and the annual cost of treating FASD in Canada and U.S. exceeds $\$ 6$ and $\$ 8$ billions, respectively (Lupton et al., 2004; Popova et al., 2013). Although, the prevention of FASD is a high priority, the failure to prevent it is attributed to our alcohol culture. Most people drink for social and recreational purposes. Others are addicted to alcohol.

As it stands, there is no consensus on whether there is a "safe" limit for alcohol consumptions during pregnancy. Recent research involving animal (mice) models has shown that continuous exposure of low-to-moderate dose of alcohol during pregnancy impacts behavioral and cognitive outcomes of resulting pups (Kleiber et al., 2011) and even a single binge dose of alcohol at any time during pregnancy results in alterations in gene expression (Kleiber et al., 2012, 2013) and associated FASD related phenotypes. Furthermore, the molecular alterations may be initiated and maintained for life by alcohol's effect on epigenetic features that includes DNA methylation (Laufer et al., 2013). The results on animal models argue that clinical features of FASD represent "tip of the iceberg." They are also backed by results on humans. For example, exposure of human embryonic stem cells to low alcohol can alter gene expression leading to the abnormal development of prefrontal cortex (Krishnamoorthy et al., 2010). Also, fetal alcohol exposed school children show "a small but potentially important detrimental effect” on educational outcomes (Zuccolo et al., 2013) as well as generalized deficit of conceptualization (Quattlebaum and O'Connor, 2013).

We feel that such results deserve due consideration given that Royal College of Obstetrics and Gynecologists (Royal College of Obstetrician and Gynaecology, 2006) states that, "there is no evidence of harm from low levels of alcohol consumption, defined as no more than one or two units of alcohol once or twice a week." Also, "there is considerable doubt as to whether infrequent and low level of alcohol consumption during pregnancy convey any long-term harm" - in other words they suggest a safe amount of alcohol consumption in pregnancy. Unfortunately, this limit has not been defined and may vary from individual to individual. Individual women process alcohol differently. Also, the age of the mother, the timing and regularity of the alcohol ingestion, and whether the mother has eaten any food while drinking may be important. We argue that there is no logistic evidence to define this limit. What is needed is to undertake thorough studies on neurodevelopment and assess the significance of such factors as maternal and fetal genotype, stress during pregnancy and childbirth, prenatal drinking patterns (mild, medium, heavy), post-natal environment, and socioeconomic status, as most of these may contribute to the manifestation of the effect of prenatal alcohol on the newborn. We note that some of these studies will be problematic if not impossible on humans. The rational question is "does no evidence of harm from low levels of alcohol consumption means $100 \%$ exclusion of the possibility of any harm to the fetus?" To the best of our understanding the answer is "no."

The issue is particularly problematic as there is a rise in heavy drinking by young people, particularly women. Often, it is 
framed, as freedom of choice or "a single drink will not harm.” Not surprisingly, 1 in 8 adult women and 1 in 5 high school girls binge drink (CDC, 2013) and there is ample evidence from animal experiments, which argue for a life-long effect of even a single exposure of alcohol during pregnancy. The developing brain is a sequential, multistage, closely orchestrated, and highly sensitive to stresses. Also, any aberration could lead to life-long abnormality. For now, it is prudent to prevent a brain disorder than to attempt to ameliorate or cure it. Preventing a single case of FASD will save the society $\$ 1$ million. More importantly it will save a productive life. The business as usual model is not helpful. It continues to result in births with alcohol effects. Any harm caused by prenatal alcohol is currently not reversible. It will affect the child for life.

With the current knowledge of what causes FASD it is prudent to stay on the safe side and avoid any drinking during and around the pregnancy. FASD is an alcohol problem. It is possible to prevent this calamity by avoiding alcohol during pregnancy and the time is now! FASD is a preventable disease-by not drinking during pregnancy. On the other hand, finding "cure" will be much more challenging, costly and time taking. It is critical to undertake active measures to reduce the occurrence of this disorder by a message of "no alcohol dose is guaranteed to be $100 \%$ safe for the embryo/fetus." Also, "no time during pregnancy is $100 \%$ safe to drink." Any adult has the right to drink if they so wish. Also, every child has the right to be born healthy!

\section{REFERENCES}

Barry, K. L., Caetano, R., Chang, G., DeJoseph, M. C., Miller, L. A., O’Connor, M. J., et al. (2009). Reducing Alcohol- Exposed Pregnancies: A Report of the National Task Force on Fetal Alcohol Syndrome and Fetal Alcohol Effect. Atlanta, GA: Centers for Disease Control and Prevention.

CDC. (2013). Vital signs: binge drinking among women and high school girls-United States, 2011. MMWR Morb. Mortal. Wkly. Rep. 62, 9-13. Available online at: http://www.cdc.gov/mmwr/ preview/mmwrhtml/mm6201a3.htm

Jones, K. L., and Smith, D. W. (1973). Recognition of the fetal alcohol syndrome in early infancy. Lancet 302, 999-1001. doi: 10.1016/S0140-6736(73) 91092-1

Kleiber, M. L., Laufer, B. I., Wright, E., Diehl, E. J., and Singh, S. M. (2012). Long-term alterations to the brain transcriptome in a maternal voluntary consumption model of fetal alcohol spectrum disorders. Brain Res. 1458, 18-33. doi: 10.1016/j.brainres.2012.04.016

Kleiber, M. L., Mantha, K., Stringer, R. L., and Singh, S. M. (2013). Neurodevelopmental alcohol exposure elicits long-term changes to gene expression that alter distinct molecular pathways dependent on timing of exposure. J. Neurodev. Disord. 5:6. doi: 10.1186/1866-1955-5-6

Kleiber, M. L., Wright, E., and Singh, S. M. (2011). Maternal alcohol drinking in $\mathrm{C} 57 \mathrm{BL} / 6 \mathrm{~J}$ mice: advancing a model for fetal alcohol spectrum disorder. Behav. Brain Res. 223, 376-387. doi: 10.1016/j.bbr.2011.05.005

Krishnamoorthy, M., Gerwe, B. A., Scharer, C. D., Heimburg-Molinaro, J., Gregory, F., Nash, R. J., et al. (2010). Low ethanol concentration alters CHRNA5 RNA levels during early human development. Reprod. Toxicol. 30, 489-492. doi: 10.1016/j.reprotox.2010. 04.011

Laufer, B. I., Mantha, K., Kleiber, M. L., Diehl, E. J., Addison, S. M., and Singh, S. M. (2013). Long lasting alterations to DNA methylation and ncRNAs could underlie the effect of fetal alcohol exposure in mice. Dis. Model. Mech. 6, 977-992. doi: $10.1242 / \mathrm{dmm} .010975$

Lupton, C., Burd, L., and Harwood, R. (2004). Cost of fetal alcohol spectrum disorders. Am. J. Med.
Genet. C Semin. Med. Genet. 127C, 42-50. doi: 10.1002/ajmg.c.30015

May, P. A., and Gossage, J. P. (2001). Estimating the prevalence of fetal alcohol syndrome - a summary. Alcohol Res. Health 25, 159-167. Available online at: http://pubs.niaaa.nih.gov/publications /arh25-3/159-167.htm

Popova, S., Lange, S., Burd, L., Chudley, A. E., Clarren, S. K., and Rehm, J. (2013). Cost of fetal alcohol spectrum disorder diagnosis in Canada. PLoS ONE 8:e60434. doi: 10.1371/journal.pone.0060434

Quattlebaum, J. L., and O'Connor, M. J. (2013). Higher functioning children with prenatal alcohol exposure: is there a specific neurocognitive profile? Child Neuropsychol. 19, 561-578. doi: 10.1080/09297049.2012.713466

Royal College of Obstetrician and Gynaecology. (2006). Alcohol Consumption and the Outcome of Pregnancy. London, UK: ROGC Statement No 5.

Zuccolo, L., Lewis, S. J., Smith, G. D., Sayal, K., Draper, E. S., Fraser, R., et al. (2013). Prenatal alcohol exposure and offspring cognition and school performance. A mendelian randomization natural experiment. Int. J. Epidemiol. 42, 1358-1370. doi: 10.1093/ije/dyt172

Conflict of Interest Statement: The authors declare that the research was conducted in the absence of any commercial or financial relationships that could be construed as a potential conflict of interest.

Received: 21 July 2014; accepted: 25 September 2014; published online: 13 October 2014

Citation: Singh SM, Laufer BI and Kapalanga J (2014)

Fetal alcohol and the right to be born healthy.... Front. Genet. 5:356. doi: 10.3389/fgene.2014.00356

This article was submitted to Epigenomics and Epigenetics, a section of the journal Frontiers in Genetics.

Copyright (C) 2014 Singh, Laufer and Kapalanga. This is an open-access article distributed under the terms of the Creative Commons Attribution License (CC BY). The use, distribution or reproduction in other forums is permitted, provided the original author(s) or licensor are credited and that the original publication in this journal is cited, in accordance with accepted academic practice. No use, distribution or reproduction is permitted which does not comply with these terms. 